\title{
EFFECT OF ECCENTRICITY OF LOAD ON CRITICAL FORCE OF THIN-WALLED COLUMNS CFRP
}

\author{
Pawel Wysmulski' ${ }^{1}$ Ján Král ${ }^{2}$
}

1 Faculty of Mechanical Engineering, Department of Machine Design and Mechatronics, Lublin University of Technology, Nadbystrzycka 36 St., 20-618 Lublin, Poland, e-mail: p.wysmulski@pollub.pl

2 Faculty of Mechanical Engineering, Centrum of Informatics, Technical University of Košice, 9 Letná St., 04200 Košice, Slovakia, e-mail: jan.kral@tuke.sk

Received: 2017.05.15

Accepted: 2017.08.01

Published: 2017.09.03

\begin{abstract}
The subject of study was a thin-walled $\mathrm{C}$-section made of carbon fiber reinforced polymer (CFRP). Column was subjected to eccentric compression in the established direction. In the computer simulation, the boundary conditions were assumed in the form of articulated support of the sections of the column. Particular studies included an analysis of the effects of eccentricity on the critical force value. The research was conducted using two independent research methods: numerical and experimental. $\mathrm{Nu}-$ merical simulations were done using the finite element method using the advanced system Abaqus ${ }^{\circledR}$. The high sensitivity of the critical force value corresponding to the local buckling of the channel section to the load eccentricity was demonstrated.
\end{abstract}

Keywords: finite element method, buckling, eccentricity load, thin-walled structures, laminate, composite CFRP.

\section{INTRODUCTION}

Modern composite laminates are characterised by high durability and low density. Owing to these properties, materials of this kind have become an object of interest for engineers and scientists. Numerous studies have been conducted on the behaviour thin-walled composite laminates in critical state $[1,3,8,9,10,14,15,16,18]$. These papers present research findings for structures subjected to axial compression. These conditions are not always met in real structures which may be subjected to eccentric compression. In the case of this research, the structural element is subjected to compressive force shifted from the cross-section centre of mass. Theses $[11,12,13]$ were devoted to the analysis of the problem of stability loss in long composite columns (GFRP) characterised by open cross-sections eccentrically-compressed. The purpose of this study is to assess the effects of eccentricity on the behaviour of a thin-walled $\mathrm{C}$-section made of composite laminate made of carbon-fiber-reinforced polymer (CFRP).

\section{OBJECT OF THE STUDY}

The object of the study is a short, thin-walled C-section, subjected to eccentric compression. The samples were produced by autoclave and it was made of a carbon-fibre reinforced polymer. The composite lay-up consists of 8 layers in a symmetric arrangement relative to the central plane. The configuration of the composite layers is $[0 /-45 /+45 / 90]$ s. Figure 1 presents a scheme of axially-compressed C-section as well as the "e" axis indicating the direction of the measurement of the eccentric load. Eccentric was defined as the shift distance of the compressive force along the central axis of inertia measured from the cross-section centre of mass. It was assumed 


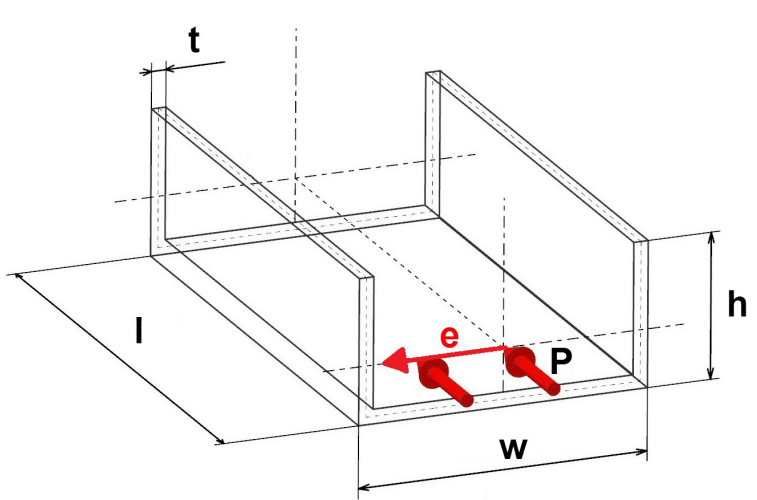

Fig. 1. A scheme of the object of the study with the preset eccentricity axis shown

Table 1. Mechanical properties of CFRP composite

\begin{tabular}{|c|c|c|c|}
\hline \multicolumn{2}{|c|}{$\begin{array}{c}\text { Young's modulus } \\
\text { [MPa] }\end{array}$} & $\begin{array}{c}\text { Kirchhoff's } \\
\text { modulus [MPa] }\end{array}$ & $\begin{array}{c}\text { Poisson's } \\
\text { ratio } \mathbf{v}_{\mathbf{1 2}}\end{array}$ \\
\hline $0^{\circ}\left(\mathrm{E}_{1}\right)$ & $90^{\circ}\left(\mathrm{E}_{2}\right)$ & $\pm 45^{\circ}\left(\mathrm{G}_{12} / \mathrm{G}_{23} / \mathrm{G}_{13}\right)$ & \multirow{2}{*}{0.32} \\
\hline 130710 & 6360 & 4180 & \\
\hline
\end{tabular}

that the distance may change within the range of $0<\mathrm{e}<10 \mathrm{~mm}$, the channel-section profile had the overall dimensions of $\mathrm{w}=80 \mathrm{~mm}, \mathrm{~h}=40 \mathrm{~mm}, \mathrm{l}=$ $143 \mathrm{~mm}$, a wall thickness of $\mathrm{t}=1.048 \mathrm{~mm}$.

The mechanical properties of a single layer of the composite material were determined in experimental tests according to the relevant ISO standard. The mechanical properties of the CFRP laminate are shown in Table 1.

\section{RESEARCH METHODOLOGY}

Detailed study of the thin-walled C-sections subjected to eccentric compression was conducted with the use of finite element method. FEM model was validated in experimental tests $[2,4,5,6,7,16,17,18]$. The C-section profile used during the experimental tests and the discrete model is shown in Figure 2.

The purpose of the conducted numerical computations was to develop adequate, experimentally validated FEM models allowing the analysis of the effect of eccentric load. The numerical model was created using SHELL elements. 8-node S8R elements were used described by a second-order shape function and reduced integration. Boundary conditions were assumed in order to reflect the articulated support of the end sections of the profile.

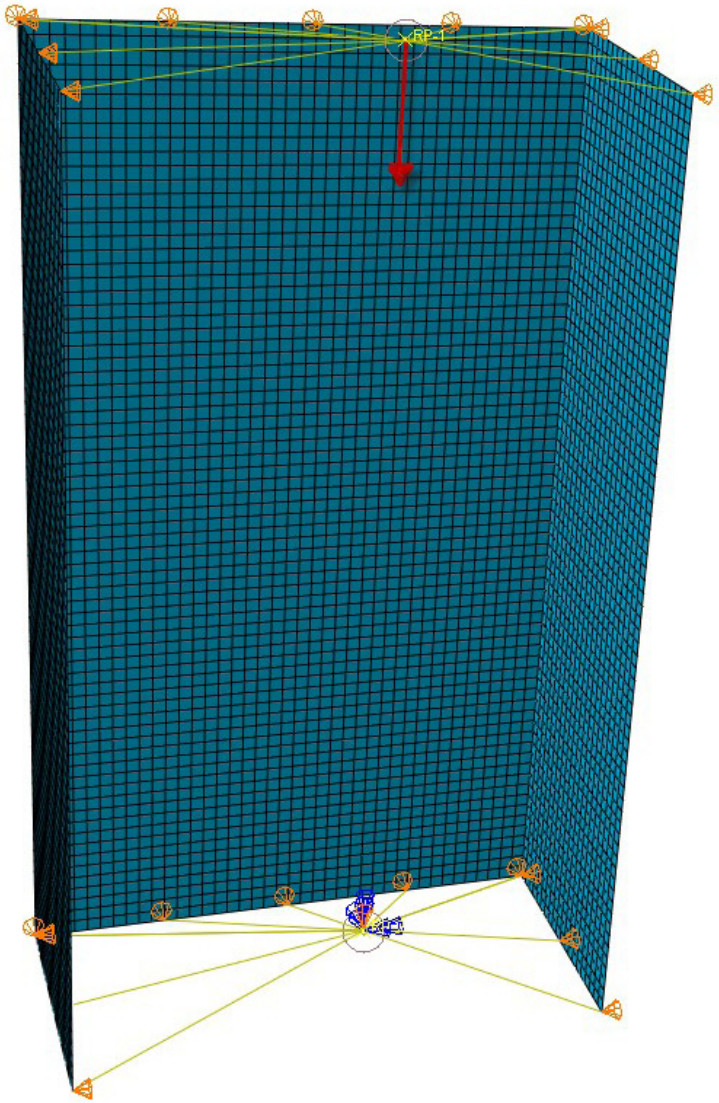

Fig. 2. Numerical model FEM during eccentric compressive load study e $=10 \mathrm{~mm}$

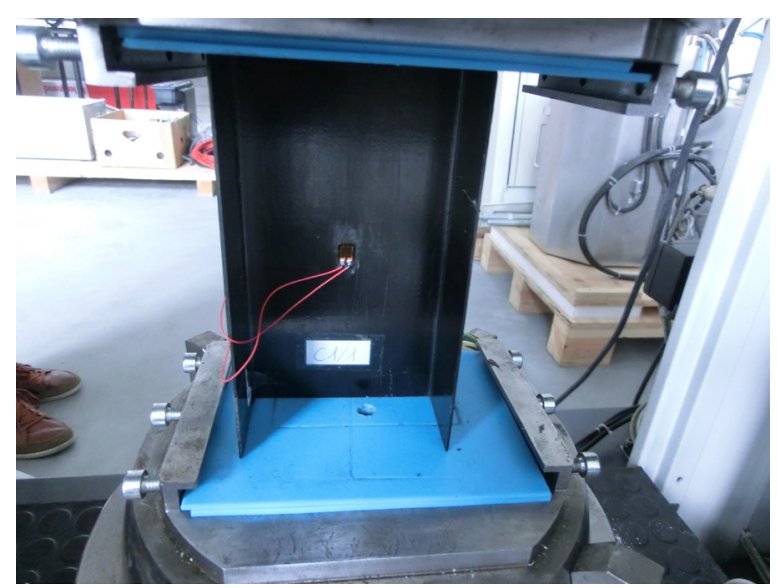

Fig. 3. Real column during eccentric compressive load study e $=10 \mathrm{~mm}$

To ensure the desired eccentricity of load, reference points coupled with the end sections by the interactive Coupling Method. The points were ascribed the boundary conditions describing axial compression. Eccentricity was ensured by the modification of the position of the reference points in the pre-set direction in 

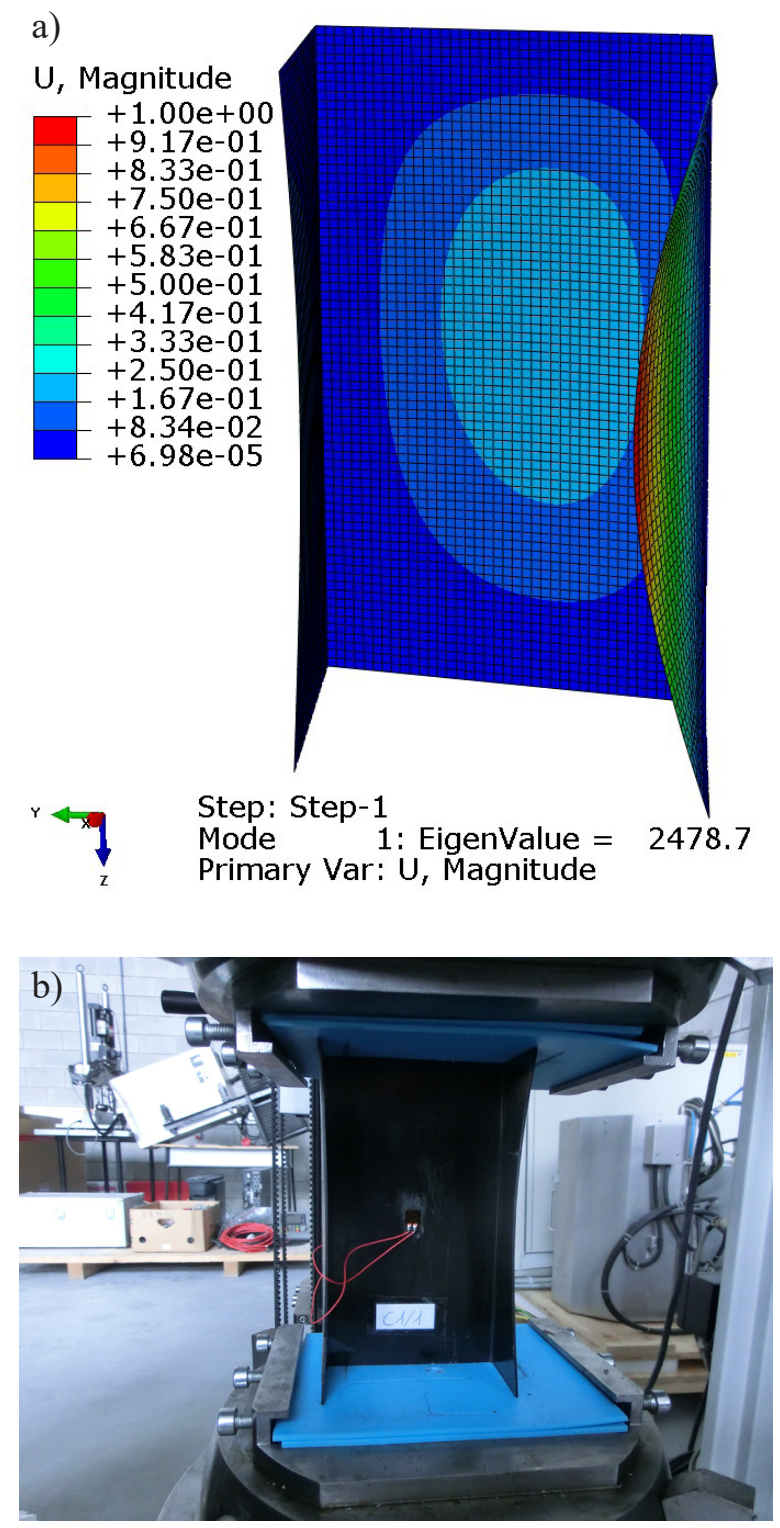

Fig. 4. The results of the analysis of compression with pre-set eccentricity e $=10 \mathrm{~mm}$ : a) numerical model, b) the experiment

the plane of the end sections. A discrete model with the applied boundary conditions used in the numerical study is shown in Figure 2.

The experiments were performed on a universal testing machine equipped with heads allowing for articulated support of the end sections of the profile. The experiment was conducted in room temperature at a constant speed of the upper cross beam set to $2 \mathrm{~mm} / \mathrm{min}$. To prevent the impact of boundary conditions on the structure, soft polymer pads were provided to ensure the proper alignment of the samples while being compressed. The test stand with mounted specimen is shown in Figure 3.
The assessment of the eccentric load during experimental tests was conducted with the use of pads allowing for the appropriate alignment of the $\mathrm{C}$-section in a pre-set distance relative to its centre of gravity. The experiment was conducted for compression $\mathrm{e}=0 \mathrm{~mm}$ and eccentric $\mathrm{e}=10 \mathrm{~mm}$. The study allowed to investigate the behaviour of the structure under pre-set compression for local buckling.

\section{RESULTS}

The study allowed to establish the modes of deformation and the corresponding values of critical forces for two variants of Csection compression. The first stage involved the analysis reflecting the conditions of axial compression, the second stage investigated the eccentric load compression. Numerical solutions of the eigenvalue problems for the presented specimens validated by the experimental C-section compression results taking into account the eccentricity of compression provided essential information, allowing for the analysis of the effects of eccentricity of load on the critical state of the structure. The lowest buckling mode of the physical specimen and numerical model for the eccentricity value $\mathrm{e}=10 \mathrm{~mm}$ is shown in Figure 4.

The solution of the eigenvalue problem involved the use of a eigensolver Subspace assuming the $\mathrm{C}$-section has no initial deflections. The type of applied study for systems characterised by a stable equilibrium path in which the second variation of potential energy must be positive. The numerical values of the critical forces was equal to the minimum potential energy of the system. This procedure allows for determining the extreme for which the system remains in equilibrium. The critical load was determined based on the experimental results using the Koiter method $[16,18]$. In order to determine the critical force it was necessary to perform an approximation using a third-order polynomial after a visible inflection of the equilibrium path $\mathrm{P}-|\mathrm{w}|$. The value of the critical force is adequate to point of intersection of polynomial and the vertical axis. The approximation range procedure was selected so as to maintain the highest possible value of the correlation coefficient $R^{2}>0,95$. Moreover, while applying the third order Koiter's method it is important to obtain a positive value of the highest degree variable. It provides a guarantee 


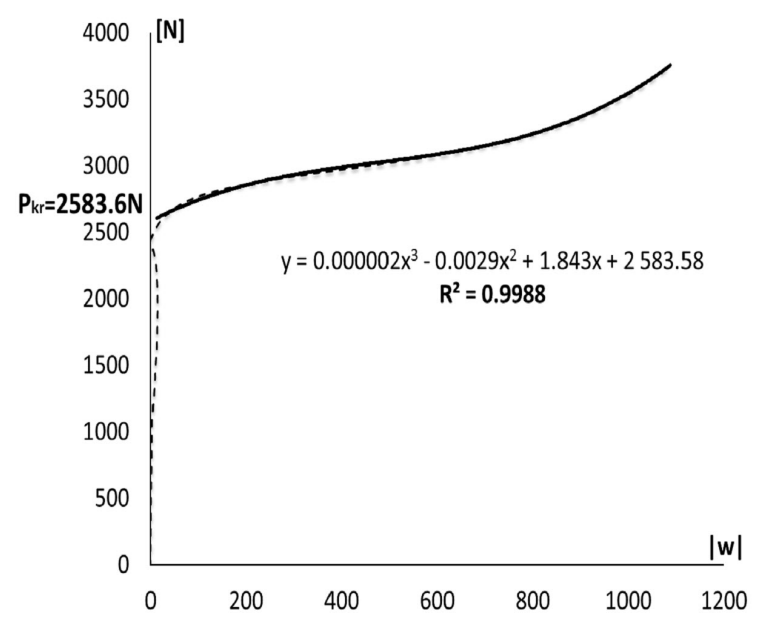

Fig. 5. Experimental determination of the critical force value for applied eccentric load e $=10 \mathrm{~mm}$

that the desired approximated function will correlate with the character of the construction stability. The process of experimental determination of the critical force value using Koiter's approximation method for eccentric compressive load $\mathrm{e}=10$ $\mathrm{mm}$ is shown in Fig. 5.

The comparison of the numerical computations results and experimental tests of the value of the critical load corresponding to the local buckling of a short $\mathrm{C}$-section composite profile is shown in Fig. 6. The stability loss in the studied specimens manifested itself as a local buckling, resulting in formation of one half-wave on the walls and on the web of the C-section profile. The results reveal a high sensitivity of the structure for the value of eccentric compression. During the experiment with applying eccentric compression, the value of the critical force de-

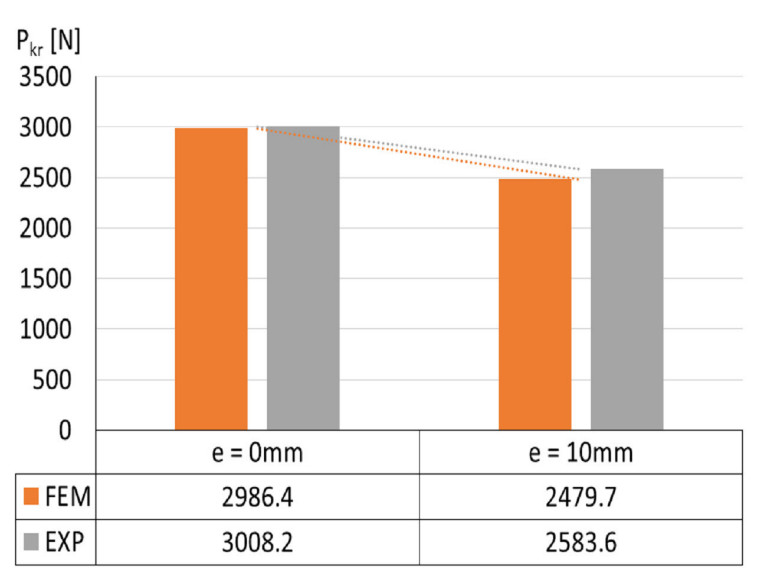

Fig. 6. Comparison of the experiment results creased considerably. For eccentricity value e = $10 \mathrm{~mm}$ the decrease in the critical force for the tested C-section was approximately 20\%. No transitions between local buckling modes were observed during the tests. Upon comparison, the numerical results and experimental results show very high correspondence of the critical force values for both axial and eccentric compressions - maximum discrepancies were no higher than $4 \%$ (for eccentric compression). The results of critical state analysis obtained from using two independent research methods are unequivocal and show the effect of eccentric compression on the decrease of the critical force.

\section{CONCLUSIONS}

The study investigated the critical state behaviour of a short, thin-walled $\mathrm{C}$-section made of multi-layered composite made of carbonfiber-reinforced polymer (CFRP), subjected to axial and eccentric compression. The numerical model of the lowest buckling mode and experimentally obtained deformation show agreement in all studied modes of compression. Koiter's approximation method was used to determine the experimental critical force achieving correlation coefficient over $\mathrm{R}^{2}=0,99$. Conducted analyses reveal high sensitivity of the model to the eccentricity of the compressive load, which is significant for operation of such structures. It was confirmed that, when applied, the eccentric load considerably decreases the critical load value resulting in loss of stability occurring at a significantly faster rate. Both numerical and experimental results of the critical load value as well as the forms of stability loss show high agreement, which confirms the adequacy of the developed numerical models.

\section{Acknowledgements}

The research has been conducted under the project No UMO-2015/19/B/ST8/02800 financed by the National Science Centre Poland.

\section{REFERENCES}

1. Debski H., Teter A., Kubiak T. and Samborski S. Local buckling, post-buckling and collapse of thin-walled channel section composite columns subjected to quasi-static compression. Composite Structures, 136, 2016, 593-601. 
2. Debski H., Koszalka G. and Ferdynus M. Application of FEM in the analysis of the structure of a trailer supporting frame with variable operation parameters. Eksploatacja i Niezawodnosc-Maintenance and Reliability, 14(2), 2012, 107-113.

3. Debski H., Teter A. and Kubiak T. Numerical and experimental studies of compressed composite columns. Composite Structures, 118, 2014, 28-36.

4. Falkowicz K. and Debski H. Postbuckling behaviour of laminated plates with a cut-out. Advances in Science and Technology - Research Journal, 11(1), 2017, 186-193.

5. Falkowicz K., Mazurek P., Rozylo P., Wysmulski P. and Smagowski P. Experimental and numerical analysis of the compression of a thin-walled composite plate. Advances in Science and Technology - Research Journal, 10(31), 2016, 177-184.

6. Gliszczyński A. and Kubiak T. Progressive failure analysis of thin-walled composite columns subjected to uniaxial compression. Composite Structures, 169, 2016, 52-61.

7. Kmet S., Stanova E., Fedorko G., Fabian M. and Brodniansky J. Experimental investigation and finite element analysis of a four-layered spiral strand bent over a curved. Engineering Structures, 57, 2013, 475-483.

8. Kolakowski Z. Static and dynamic interactive buckling of composite columns. Journal of Theoretical and Applied Mechanics, 47, 2009, 177-192.

9. Kolakowski, Z. and Mania R.J. Semi-analytical method versus the FEM for analysing of the local post-buckling of thin-walled composite structures. Composite Structures, 97, 2013, 99-106.

10. Kubiak T., Kolakowski Z., Swiniarski J., Urbaniak M. and Gliszczynski A. Local buckling and postbuckling of composite channel-section beams -
Numerical and experimental investigations. Composites Part B, 91, 2016, 176-188.

11. Mottram J.T., Brown N.D. and Anderson D. Buckling characteristics of pultruded glass fibre reinforced plastic columns under moment gradient. Thin-Walled Structures, 41, 2003, 619-638.

12. Nunes F., Correia M., Correia J.R., Silvestre N. and Moreira A. Experimental and numerical study on the structural behavior of eccentrically loaded GFRP columns. Thin-Walled Structures, 72, 2013, 175-187.

13. Ragheb Wael F. Local buckling analysis of pultruded FRP structural shapes subjected to eccentric compression. Thin-Walled Structures, 48, 2010, 709-717.

14. Rozylo P. and Lukasik D. Numerical analysis of the critical state of thin-walled structure with z-profile cross section. Advances in Science and Technology - Research Journal, 11(1), 2017, 194-200.

15. Rozylo P. and Wrzesinska K. Numerical analysis of the behavior of compressed thin-walled elements with holes. Advances in Science and Technology - Research Journal, 10(31), 2016, 199-206.

16. Rozylo P., Teter A., Debski H., Wysmulski P. and Falkowicz K. Experimental and numerical study of the buckling of composite profiles with open cross section under axial compression. Applied Composite Materials, DOI: 10.1007/s10443-0179583-y, 2017.

17. Stanova E., Fedorko G., Kmet S., Molnar V. and Fabian M. Finite element analysis of spiral strands with different shapes subjected to axial loads. Advances in Engineering Software, 83, 2015, 45-58.

18. Wysmulski P., Dębski H., Rozylo P. and Falkowicz, $\mathrm{K}$. A study of stability and post-critical behaviour of thin-walled composite profiles under compression. Eksploatacja i Niezawodnosc-Maintenance and Reliability, 18(4), 2016, 632-637. 